\title{
Off-Label Use of Drugs and Devices in the Neuroendovascular Suite
}

M.M. Abdihalim, A.E. Hassan, and A.I. Qureshi

\begin{abstract}
SUMMARY: The off-label use of drugs and devices in neuroendovascular procedures is common. Neurointerventionalists should be well aware of the level of evidence available in support of the off-label use of drugs and devices in their practice and some of the potential adverse events associated with them. These uses are categorized as I or II if they have been evaluated as primary or ancillary interventions in prospective trials/registries of neuroendovascular procedures and III if they were evaluated in case series. Category IV use is based on evaluation as primary or ancillary interventions in prospective trials/registries of non-neuroendovascular procedures. Physicians are allowed to use off-label drugs and procedures if there is strong evidence that they are beneficial for the patient. The neurointerventional professional societies agree that off-label use of drugs and devices is an important part of the specialty, but practicing providers should base their decisions on sound evidence when using such drugs and devices.
\end{abstract}

ABBREVIATIONS: GDC = Guglielmi detachable coil; IA = intra-arterial; ICH = intracerebral hemorrhage; PROACT = Prolyse in Acute Cerebral Thromboembolism; UK = urokinase

O ff-label ${ }^{1}$ use for prescription drugs, biologics, and approved medical devices is any use that is not specified in the labeling approved by the US Food and Drug Administration. Labeling includes any written material that accompanies, supplements, or explains the product. In neuroendovascular procedures practice, this use is relatively common. ${ }^{1}$ However, the knowledge among practicing neuroradiologists, endovascular neurosurgeons, and interventional neurologists regarding the principles and consequences of using off-label products in their practice is lacking.

If physicians use a product for an indication not in the approved or cleared labeling, they have the responsibility to be wellinformed about the product, to base its use on firm scientific rationale and on sound medical evidence, and to maintain awareness of the use and effects of the product. FDA regulations allow the exchange and dissemination of scientific information on the unapproved uses of a product in response to unsolicited requests from physicians, continuing medical education programs, and peer-reviewed scientific and medical journals. ${ }^{1}$

This Review Article provides data with the following objec-

From the Zeenat Qureshi Stroke Research Center (M.M.A., A.E.H., A.I.Q.) and Department of Radiology (M.M.A.), University of Minnesota, Minneapolis, Minnesota.

Please address correspondence to Mohamed Abdilhalim, MD, Department of Radiology, University of Minnesota, Diagnostic Radiology MMC 292, 420 Delaware St SE, Minneapolis, MN 55455; e-mail: abdi0018@umn.edu

- Indicates open access to non-subscribers at www.ajnr.org

三 Indicates article with supplemental on-line table

http://dx.doi.org/10.3174/ajnr.A3447 tives: 1) allowing physicians to recognize off-label use of products within the scope of their practice, 2) identifying instances when the off-label use of medical products is recognized as a generally accepted medical standard within the physician community, 3) summarizing our experience using off-label products in our practice, and 4) providing recommendations from professional organizations on off-label use of drugs and medical devices.

\section{OFF-LABEL USE OF DRUGS IN THE NEUROENDOVASCULAR SUITE}

The following summarizes the most common drugs used off-label within the neuroendovascular suite.

\section{Intra-Arterial Use of Thrombolytics}

Approved Use of Thrombolytics. For acute ischemic stroke, intravenous administration within 3 hours of symptom onset; massive pulmonary embolus; and acute myocardial infarction.

Off-Label Use. Intra-arterial administration for acute ischemic stroke up to 9 hours after symptom onset (category I). The only FDA-approved thrombolytic for acute ischemic stroke treatment is IV alteplase (Activase; Genentech, South San Francisco, California). ${ }^{2}$ Treatment should only be initiated within 3 hours after the onset of stroke symptoms and after exclusion of intracranial hemorrhage by a cranial CT scan. A subgroup of patients with ischemic stroke is treated by using intra-arterial thrombolytics with various criteria either alone or in combination with IV 
thrombolytics and/or mechanical thrombectomy. ${ }^{3,4}$ Intra-arterial urokinase (Abbokinase; Abbott Laboratories, Chicago, Illinois) was the most commonly used intra-arterial thrombolytic for acute ischemic stroke before 1999. ${ }^{5}$ However, an FDA action resulted in withdrawal of urokinase from the market for 4 years. FDA inspectors found that Abbott was not taking adequate steps to test for infection in or prevent contamination of the kidney cells used to manufacture the drug. ${ }^{6}$

This withdrawal led to use of other thrombolytic medications including prourokinase, reteplase, tenecteplase, and alteplase as part of endovascular treatment for acute ischemic stroke. ${ }^{5}$ Prourokinase was the only thrombolytic that was considered for FDA approval on the basis of the results of PROACT I and II trials. ${ }^{7,8}$ In both of those trials, patients were given intra-arterial (IA) prourokinase within 6 hours of symptoms onset. These trials demonstrated an increased rate of recanalization, $57.7 \%$ and $67 \%$ (treatment group) versus $14.3 \%$ and $18 \%$ (controls). ${ }^{7,8}$ Moreover, a recent meta-analysis of 5 randomized controlled trials of IA thrombolysis of acute ischemic stroke with 395 participants showed IA thrombolysis by using pro-UK, UK, or recombinant tissue plasminogen activator substantially increased the rates of recanalization and had excellent clinical outcomes. The increased hemorrhage frequencies were not associated with any increase in mortality. ${ }^{9}$ The off-label use of thrombolytics is recognized as a generally accepted medical standard within the physician community (category I). The formulation of thrombolytics (more concentrated compared with IV-use formulation) and the maximum dose used require sound principles or previous studies that have reported on these issues. ${ }^{10}$ Third-generation thrombolytics, tenecteplase (17 \pm 7 minutes), and reteplase (15-18 minutes), have longer half-lives and greater penetration in the thrombus matrix than alteplase (5 minutes). ${ }^{11}$

\section{Platelet Glycoprotein Ilb/IIla Inhibitors}

Approved Use. Patients with acute coronary syndrome who are treated medically only and those undergoing percutaneous coronary intervention; and patients undergoing percutaneous coronary intervention including stent placement.

Off-Label Use. Intraprocedural thrombosis and ischemic events following endovascular procedures (category III). The experience of using platelet glycoprotein IIb/IIIa inhibitors abciximab (Reopro; Johnson and Johnson, Malvern, Pennsylvania), eptifibatide (Integrillin; Merck, Whitehouse Station, New Jersey), and tirofiban (Aggrasat; Merck, West Point, Pennsylvania) in neurointerventional procedures is limited. These agents are effective in reducing ischemic complications of acute myocardial infarctions and thrombotic complications associated with percutaneous coronary interventions. ${ }^{12-14}$ The FDA-approved indications of glycoprotein IIb/IIIa inhibitors are in acute coronary syndromes and as an adjunct to percutaneous coronary interventions. The offlabel use of glycoprotein IIb/IIIa inhibitors was evaluated in several case series and clinical trials focusing on patients undergoing endovascular treatment for acute ischemic stroke or those undergoing carotid artery stent placement. ${ }^{15-17}$ The use of platelet glycoprotein IIb/IIIa inhibitors in both of these applications was discontinued for the most part. The premature discontinuation of the Abciximab in Emergency Treatment of Stroke Trial II after 808 patients with acute ischemia were enrolled due to high rates of intracranial hemorrhage associated with IV abciximab (IV bolus followed by IV infusion) limited the enthusiasm for further evaluation in ischemic stroke. ${ }^{18}$ The routine use in carotid artery stent placement was discontinued after a randomized trial, and 2 single-center comparisons with historical controls did not demonstrate any reduction in periprocedural ischemic events. ${ }^{19-21}$ The relatively high rate of fatal intracerebral hemorrhages (ICHs) observed in studies also reduced the enthusiasm for using these agents. ${ }^{22}$ Some local institutional review boards may require that planned use of these agents involve informing patients or relatives regarding such complications. The current use in neuroendovascular procedures is limited to intraprocedural thrombosis and ischemic events (category III). ${ }^{16,23,24}$ Glycoprotein IIb/IIIa inhibitors are approved only for IV administration but are usually administered by IV infusion, IA bolus followed by IV infusion, or IV bolus followed by IV infusion. ${ }^{15}$

Physicians administering these agents should be well aware of the principle of dose conversion of any agent requiring special formulation, reversal half-lives, and monitoring for thrombocytopenia. Abciximab requires filtration, while eptifibatide and tirofiban do not, before administration. Dosing of both eptifibatide and tirofiban should be adjusted in patients with renal failure (renal elimination) but this is not necessary with abciximab (eliminated by the reticuloendothelial system). ${ }^{25}$ Although rare, thrombocytopenia can occur within 1-24 hours after infusion. ${ }^{26}$ When these agents are infused, platelets should be monitored 1-2 hours after infusion and again 24 hours after infusion. Platelets should recover rapidly after discontinuation. ${ }^{27}$ The off-label use of platelet glycoprotein IIb/IIIa inhibitors is recognized as a generally accepted medical standard within the physician community in certain situations such as intraprocedural thrombosis.

\section{Calcium Channel Blockers}

Approved Use. Cerebral vasospasm (nimodipine), hypertension, angina, atrial arrhythmia, and paroxysmal supraventricular tachycardia.

Off-Label Use. Intra-arterial administration for improving arterial luminal narrowing in patients with symptomatic cerebral vasospasm due to subarachnoid hemorrhage in native intracranial arteries (category III).

Randomized controlled trials have shown that oral nimodipine (Nimotop; Bayer, West Haven, Connecticut) is effective in reducing delayed ischemic neurologic deficits caused by cerebral vasospasm following subarachnoid hemorrhage. ${ }^{28-30}$ Nimodipine, $60 \mathrm{mg}$ orally every 4 hours for 21 consecutive days started within 96 hours of subarachnoid hemorrhage, is FDA-approved to prevent cerebral vasospasm. ${ }^{31}$

Intra-arterial or intravenous use of verapamil, nimodipine (Nimotop), and nicardipine (Cardene; Baxter Healthcare, Deerfield, Illinois) have all been reported to be effective and safe in the treatment of cerebral vasospasm (category III). ${ }^{10,32-35}$ The offlabel use of calcium channel blockers in treating cerebral vasospasm is recognized as a generally accepted medical practice within the physician community; however, the treating physician

AJNR Am J Neuroradiol 34:2054-63 Nov 2013 www.ajnr.org 
must ensure that adequate hemodynamic monitoring is performed on patients receiving these agents. Low doses of intraarterial calcium channel blockers were not associated with significant hemodynamic changes, but high-dose nicardipine was associated with hypotension. ${ }^{34}$ The duration of monitoring must be adequate on the basis of the half-life of the agent: verapamil (4 minutes), nimodipine ( 7 minutes), and nicardipine (3 minutes). Physicians must also be familiar with and prepared to address commonly observed adverse events of hypotension and bradycardia. These agents are all category $\mathrm{C}$ medications during pregnancy.

\section{Magnesium Sulfate}

Approved Use. Atrial paroxysmal tachycardia, eclampsia, cerebral edema, barium poisoning, seizures associated with epilepsy, glomerulonephritis, or hypothyroidism.

Off-Label Use. Intra-arterial administration for improving arterial luminal narrowing in patients with symptomatic cerebral vasospasm due to subarachnoid hemorrhage in native intracranial arteries (category III).

Magnesium sulfate is a noncompetitive calcium channel blocker. ${ }^{36}$ Suarez et $\mathrm{al}^{37}$ reviewed 17 studies including a single phase III randomized controlled trial and 6 phase II randomized controlled trials on the effects of magnesium sulfate on cerebral vasospasm. They reported that the studies suggested either no net benefit or uncertain trade-offs. ${ }^{37}$ Shah et $\mathrm{al}^{38}$ reported that a combination of IA magnesium (0.25-1 g) and nicardipine (2.5-20 $\mathrm{mg}$ ) was well-tolerated in a small case series of patients with cerebral vasospasm.

\section{Heparin, Low-Molecular-Weight Heparin, and Direct Thrombin Inhibitors}

Approved Use. Multiple indications including venous thrombosis or thromboembolism, pulmonary embolism, cardiac surgery, and heparin-induced thrombocytopenia requiring anticoagulation (direct thrombin inhibitors).

Off-Label Use. Continuous infusion or intermittent boluses during neuroendovascular procedures (category II). Heparin is primarily used in neurointerventional procedures to reduce the risk of perioperative and immediate postoperative ischemia. ${ }^{39}$ Measurement of the activated coagulation time is the preferred method for evaluation of responses to heparin because the activated coagulation time demonstrates a linear heparin dose-response curve, even at the higher doses used during interventional procedures. ${ }^{5}$ The target activated coagulation time in neurointerventional procedures is $250-350$ seconds. ${ }^{39}$ Vance et $\mathrm{al}^{40}$ found that the administration of heparin is safe during the first 24 hours after endovascular treatment of ruptured intracranial aneurysms. The measurement of the intensity of anticoagulation by activated coagulation time requires understanding of the methods and instruments used for such measurements. ${ }^{41}$

Unlike unfractionated heparin and low-molecular-weight heparin, direct thrombin inhibitors such as bivalirudin (Angiomax; The Medicines Company, Parsippany, New Jersey), lepirudin (Refludan; Bayer), or argatroban (Argatroban; GlaxoSmith-
Kline, Research Triangle Park, North Carolina) are antithrombin III-independent inhibitors of thrombin that are effective against thrombin even after it binds to fibrin. Direct thrombin inhibitors are not associated with heparin-induced thrombocytopenia. ${ }^{5} \mathrm{Di}$ rect thrombin inhibitors are primarily used for the anticoagulation of patients with heparin-induced thrombocytopenia or those who are at risk for heparin-induced thrombocytopenia. ${ }^{42} \mathrm{~A}$ recent small retrospective study showed that a bivalirudin bolus of $0.6 \mathrm{mg} / \mathrm{kg}$ followed by an infusion of $1.25 \mathrm{mg} / \mathrm{kg} / \mathrm{h}$ until the target activated coagulation time was achieved was a safe alternative to heparin infusion for anticoagulation during neuroendovascular procedures. $^{43}$

\section{Aspirin and Clopidogrel}

Approved Use. Aspirin: anesthesia, antipyretic, anti-inflammatory, myocardial infarction, prophylaxis for myocardial infarction, and cerebrovascular accident. Clopidogrel: percutaneous coronary intervention for non-ST elevation myocardial infarction, prophylaxis for cerebrovascular accident, myocardial infarction, and peripheral arterial disease.

Off-Label Use. Combined aspirin and clopidogrel after intracranial or craniocervical angioplasty and/or stent placement to prevent thrombosis and ischemic complications (category II). Aspirin leads to: irreversible inhibition of platelet cyclooxygenase-1 and production of thromboxane $\mathrm{A}_{2}$, resulting in platelet inhibition. ${ }^{5}$ Aspirin is commonly used in the prevention of thromboembolic events during or following neurointerventional procedures such as aneurysm embolization or carotid and intracranial stent placement. ${ }^{44}$ van den Bergh et $\mathrm{al}^{45}$ showed that the use of antiplatelets during or after aneurysm embolization improved outcome in patients with SAH in the International Subarachnoid Aneurysm Trial. Several retrospective case series showed that antiplatelet therapy with aspirin and/or clopidogrel reduced thromboembolic events of coil embolization for unruptured intracranial aneurysms. ${ }^{46,47}$ Clopidogrel (Plavix; Sanofi Aventis, Bridgewater, New Jersey) inhibits the binding of adenosine diphosphate to its platelet receptor, leading to inhibition of platelet aggregation. ${ }^{5}$ It is approved for the prevention of stroke in patients with recent history of stroke, myocardial infraction, or established peripheral arterial disease. $^{48,49}$

Dual antiplatelet therapy is routinely used after intracranial angioplasty and intracranial or extracranial stent placement. However, the duration of dual antiplatelet therapy is not well-defined. ${ }^{50}$ Most of the data regarding periprocedural antiplatelet management are derived from the coronary interventional literature. ${ }^{51}$ A retrospective case series recently did not show increased adverse events from dual antiplatelet therapy beyond 1 month of the endovascular procedure. ${ }^{51}$ Several large prospective multicenter trials (category II) have used aspirin and clopidogrel at least 3 days before the procedure and continued to 1-3 months after carotid artery stent placement (Carotid Revascularization Endarterectomy vs. Stenting Trial [CREST]/ Stenting and Angioplasty with Protection in Patients at High Risk for Endarterectomy [SAPPHIRE]/International Carotid Stenting Study [ICSS]/ Stent-Protected Angioplasty vs. Carotid Endarterectomy in Symptomatic Patients [SPACE]) and intracranial stent placement (Stenting vs. Aggressive Medical Management for Preventing Recur- 
rent stroke in Intracranial Stenosis [SAMMPRIS]). ${ }^{52-56}$ The safety and tolerability of these medications for a month following the procedure has been ascertained in 3121 patients with a very low rate of ICH (1.6\%). ${ }^{52-56}$ Two of the above trials (CREST and SAMMPRIS) permitted a bolus dose of clopidogrel ( 450 or $600 \mathrm{mg}$ ) if it could not be administered at least 3 days before the procedure. ${ }^{44}$ Physicians should be aware of the risk of thrombotic thrombocytopenia purpura and bone marrow suppression with clopidogrel, which occurs in 1 case per 8500-26,000 patients treated with clopidogrel.

\section{MEDICAL DEVICES}

\section{Intracranial and Extracranial Stent Placement}

Drug-eluting balloon-expandable, bare-metal balloon-expandable, and self-expanding stents have all been used to treat medically refractory intracranial stenosis. ${ }^{52,57-67}$ These case series suggested that intracranial stent placement can be performed safely and with high technical success.

\section{Drug-Eluting Stents}

Approved Use. Improving coronary luminal narrowing in patients with symptomatic ischemic disease due to de novo lesions in native coronary arteries.

Off-Label Use. Improving arterial luminal narrowing in patients with symptomatic ischemic disease due to de novo lesions in native intracranial arteries (category III). Drug-eluting stents indicated for coronary artery disease have significantly reduced restenosis rates. ${ }^{68}$ Common drug-eluting stents include the Taxus Express (Boston Scientific, Natick, Massachusetts), which elutes paclitaxel; Cypher (Cordis, Miami Lakes, Florida), which elutes sirolimus; and Endeavor (Medtronic, Minneapolis, Minnesota), which elutes zotarolimus. There are no large trials evaluating the safety and efficacy of drug-eluting stents in the intracranial circulation, to our knowledge. Case series report on the use of Cypher and Taxus stents for intracranial stenosis and more frequently vertebral artery-origin stenosis (category III). Intracranial application of drug-eluting stents has been limited by their inflexibility, the tortuous nature of intracranial vessels, and the high rate of late stent thrombosis requiring prolonged dual antiplatelet use. ${ }^{69,70}$ The benefit demonstrated in prevention of restenosis is less obvious in neurovascular applications. Fields et $\mathrm{al}^{65}$ reported a restenosis rate of $21 \%$ with drug-eluting stents at the vertebral origin (3/14) and 38\% (3/8) with intracranial use. Overall, restenosis rates were comparable with restenosis rates of bare metal stents. The off-label use must be performed with the understanding of the current guidelines for antiplatelet treatment with drug-eluting stents, which require 12 months of dual antiplatelet therapy and low-dose aspirin continued indefinitely. ${ }^{71}$

\section{Balloon-Expandable Stents}

Approved Use. Improving coronary luminal narrowing in patients with symptomatic ischemic disease due to de novo lesions in native coronary arteries.

Off-Label Use. Improving arterial luminal narrowing in patients with symptomatic ischemic disease due to de novo lesions in native intracranial arteries (category III).
The nonrandomized multicenter Stenting of Symptomatic Atherosclerotic Lesions in the Vertebral or Intracranial Arteries trial, which tested the Neurolink system (Guidant, St. Paul, Minnesota), showed 30-day and 1-year stroke rates of $7.2 \%$ and $10.9 \%$, respectively. Recurrent stenosis occurred in $35 \%$ at 6 months. ${ }^{67}$ The Neurolink stent was approved on the basis of that result on a Human Device Exemption approval; however, that stent is no longer being manufactured. Cruz-Flores and Diamond ${ }^{72}$ reported a systematic review of 79 studies (1999 cases) on the efficacy and safety of intracranial artery angioplasty and stent placement for intracranial artery stenosis. The rate for perioperative stroke was $8 \%$; perioperative death, $3 \%$; perioperative stroke or death, 10\%; and other perioperative complications (such as groin hematoma and arterial dissection), 10\%. Additionally, in those studies with follow-up of at least 1 year, the risk of stroke or death was $6 \% .^{73}$

Qureshi et $\mathrm{al}^{73}$ reported on the complications following angioplasty and/or stent placement in 92 patients in 3 medical centers. They found a nonsignificantly higher rate of periprocedural adverse events with balloon-expandable stents. However, Kurre et $\mathrm{al}^{74}$ analyzed the large INTRASTENT registry, a European multicenter registry, and found no statistically significant difference in complications between 254 lesions treated with balloon-expandable stents and 155 lesions treated with self-expanding stents. Some examples of balloon-expandable stents include AVE S660 (Medtronic), BX sonic (Cordis), and Multi-Link (Abbott Vascular, Redwood, California). The off-label use of balloon-expandable stents for intracranial stenosis is category III. The unique technical challenges in placement with long intracranial lesions must be recognized.

The Apollo Stent for Symptomatic Atherosclerotic Intracranial Stenosis (ASSIST) study reported that stent-delivery failure was more frequent in lesions of $>10 \mathrm{~mm}$ compared with those of $<10$ $\mathrm{mm}(25 \%$ versus $3 \%)$, though no relationship could be demonstrated with periprocedural stroke and death. The presence of tortuous proximal vessels ( $\geq 2$ acute curves requiring traversing, judged by experience or trial), limited vessel length available distal to the lesion to allow stable placement of microwire, or the inability to place a guide catheter in the distal vertebral artery or internal carotid artery resulted in a higher technical failure rate than that reported for "onlabel" indications. ${ }^{75}$ The operator must be familiar with the inflation and deployment profiles of balloon-expandable stents to avoid excessive distention of the arterial wall and difficulties with deployment in contiguous arterial segments with major differences in diameter such as the vertebral-basilar junction.

\section{Coronary Angioplasty Balloons for Intracranial Angioplasty}

Approved Use. Improving coronary luminal narrowing in patients with symptomatic ischemic disease due to de novo lesions in native coronary arteries.

Off-Label Use. Improving arterial luminal narrowing in patients with symptomatic ischemic disease due to de novo lesions in native intracranial arteries (category III).

In a systematic review of 69 studies (33 primary angioplasty studies with coronary angioplasty balloons with a total of 1027 
patients and 36 stent-placement studies with a total of 1291 patients), there were 91 strokes and deaths reported in the angioplasty-treated group compared with 104 in the stent-treated group during a 1 -month period $(P=.5)$. The 1 -year stroke and death rate in patients treated with angioplasty was $20 \%$ compared with $14 \%$ in the stent-treated patients $(P=.009)$. The pooled restenosis rate was $14 \%$ in the angioplasty-treated group compared with $11 \%$ in the stent-treated group $(P=.04)$. No effect of the publication year of the studies was seen on the risk of stroke and death. ${ }^{76}$ Common balloon catheters used for intracranial angioplasty included the Maverick (Boston Scientific), Ninja (Cordis), and Gemini (Guidant). New generations of semicompliant balloon catheters such as Gateway (Boston Scientific) with hydrophilic coating designed for low-pressure inflations and high navigability have been introduced recently, specifically for intracranial use. No clear data support the superiority of such angioplasty catheters over the existing coronary angioplasty catheters.

\section{Self-Expanding Stents for Intracranial or Extracranial Dissections}

Approved Use. Intracranial stenosis (Wingspan; Boston Scientific) and stent-assisted embolization of aneurysms (Neuroform; Boston Scientific).

Off-Label Use. Improving arterial luminal narrowing and reducing irregularity in patients with symptomatic ischemic disease due to arterial dissections in native intracranial or extracranial arteries (category III).

The Wingspan self-expandable stent and Gateway balloon (Boston Scientific) are currently an FDA-approved intracranial stent and angioplasty balloon system for intracranial atherosclerotic stenosis; and the Neuroform self-expandable stent (Boston Scientific) is currently approved for stent-assisted embolization of wide-neck intracranial aneurysms that are not candidates for surgical treatment. Both stents have been used for treatment of intracranial dissections. Other self-expandable stents used in extracranial and vertebral artery dissections include the X-pert SelfExpanding Stent System (Abbott Vascular), approved for palliation of malignant strictures in the biliary system, and the Fluency Plus (Bard Peripheral Vascular, Tempe, Arizona); and carotid artery stents are approved for atherosclerotic stenosis of the ICA. ${ }^{76-79}$ Both the Wingspan and Neuroform stents have been used for treatment of extracranial dissections. There are some data that support a high technical success rate and long-term patency of these stents in intracranial or extracranial dissections (category III). ${ }^{80}$ However, the operator must be aware that there are limited data on the comparative efficacy with medical treatment alone and long-term angiographic patency following the procedure.

\section{Carotid Balloon Angioplasty}

Approved Use. Aviator Plus and Savvy (Cordis) and Symmetry (Boston Scientific) in improving coronary or peripheral artery luminal narrowing in patients with symptomatic coronary artery or peripheral arterial disease.

Off-Label Use. Improving carotid artery luminal narrowing (category III). Carotid atherosclerotic disease is implicated in 15\%-
$30 \%$ of all ischemic strokes. ${ }^{81}$ Multiple studies have shown that carotid artery angioplasty and stent placement have long-term outcomes similar to those in carotid artery endarterectomy for patients with carotid artery disease. ${ }^{49,53-56}$ Currently, the Aviator Plus and Viatrac 14 Plus are the only 2 angioplasty balloon catheters approved for carotid angioplasty. However, many different types of angioplasty balloons with unique properties approved for coronary artery or peripheral artery angioplasty have been used off-label for carotid artery angioplasty. ${ }^{82,83}$ Understanding of the differences in angioplasty balloon properties is essential. Angioplasty balloon catheters can be grouped into 5 categories, as follows: standard (0.035-inch) balloon catheters (eg, Ultra-Thin Diamond; Boston Scientific), small-vessel (0.014/0.018-inch) balloon catheters (eg, Coyote, Sterling SL, and Symmetry; Boston Scientific and SLEEK and SAVVY; Cordis), high-pressure balloon catheters (eg, Mustang; Boston Scientific and Dorado and Conquest; Bard Peripheral Vascular, Tempe, Arizona), large-vessel balloon catheters (eg, XXL; Boston Scientific and Atlas; Bard Peripheral Vascular, Tempe Arizona), and special angioplasty balloon catheters (eg, Cutting Balloon and PolarCath; Boston Scientific). ${ }^{84}$

\section{Balloon Angioplasty for Cerebral Vasospasm}

Approved Use. Improving coronary luminal narrowing in patients with symptomatic ischemic disease due to de novo lesions in native coronary arteries.

Off-Label Use. Improving arterial luminal narrowing in patients with symptomatic cerebral vasospasm due to subarachnoid hemorrhage in native intracranial arteries (category III).

Balloon angioplasty for symptomatic or angiographic cerebral vasospasm has been shown to improve clinical outcomes (category III). ${ }^{85-87}$ Angioplasty provides the most improvement in reducing vasospasm in patients with subarachnoid hemorrhage presenting with low Hunt and Hess scale SAH (I or II) and if performed within 12 hours of symptom onset. ${ }^{86,87}$ In a recent small series of 30 patients, no difference was noted between compliant and noncompliant balloons for the angioplasty of cerebral vasospasm. ${ }^{88}$ This group compared compliant balloons (HyperGlide or HyperForm; ev3, Irvine, California) or noncompliant balloons (Maverick or Gateway, Boston Scientific; Sprinter, Medtronic; and Voyager, Abbott Vascular). Achieving normal or supranormal vessel-lumen diameter after the first angioplasty was associated with significant reduction in future angioplasties. ${ }^{88}$ The main complications of balloon angioplasty are rare but include rupture or occlusion of the vessel. ${ }^{85,89-91}$ In addition, balloon angioplasty proximal to an unsecured aneurysm may result in aneurysmal rupture. ${ }^{90,91}$

\section{Intravascular Sonography}

Approved Use. Diagnostic sonography of the peripheral and coronary vasculature.

Off-Label Use. Sonography of the carotid and intracranial vasculature (category III). Intravascular sonography has many potential applications in neurointerventional practice. ${ }^{92}$ It can be used in the determination of the morphology and composition of ath- 
erosclerotic plaque within the extracranial and intracranial circulation, mural thrombus, plaque ulceration, and aneurysm and vessel dissection; it allows evaluation of correct stent diameter required and the amount of balloon-inflation pressure needed during angioplasty; and it enables visualization of stent apposition and expansion. Currently there are no FDA-approved intravascular sonographic devices for intracranial application. Several studies have shown that intravascular sonography is safe in the intracranial circulation. ${ }^{93-96}$ Clark et $\mathrm{al}^{93}$ prospectively evaluated the safety of intravascular sonography in carotid stent placement in 98 patients. They had an acceptable 30-day stroke rate and combined stroke and death rates of $5 \%$ and $6 \%$, respectively (category III).

\section{Embolic Agents for Aneurysms, Tumors, and Epistaxis}

Approved Use. Vascular malformations.

Off-Label Use. Aneurysms, tumors, and epistaxis (category III). Onyx (ev3), n-butyl cyanoacrylic acid ( $n$-BCA) (Trufills; Cordis), and polyvinyl alcohol particles have all been approved for treating cerebral arteriovenous malformations. ${ }^{97}$ However, they have also been used in treating intracranial aneurysms, epistaxis, tumors, and dissecting vertebral artery aneurysms. ${ }^{98-106}$ The FDA approved a high-viscosity type of Onyx (Onyx HD500) as a Humanitarian Use Device for wide-neck aneurysms $(>4 \mathrm{~mm}$ or domeneck ratio of $<2$ ) that are not amenable to surgical treatment. ${ }^{107}$ Onyx HD500 is safe and effective for treating wide-neck aneurysms that are not amenable to other techniques. Piske et al ${ }^{107}$ reported complete aneurysm occlusion of 65.5\% (postprocedure), $84.6 \%$ (6 months), and $90.3 \%$ (18 months) in 84 aneurysms treated with Onyx HD500 with a peri-procedural mortality rate of $2.9 \%$. Small case series have shown that $n$-BCA is safe and effective for the embolization of distal small intracranial aneurysms. ${ }^{105,106}$ In experimental models, polyvinyl alcohol has been shown to be effective in the embolization of aneurysms. ${ }^{108,109}$

Polyvinyl alcohol, gelatin sponge pledgets (Gelfoam; Pfizer, New York, New York), and trisacryl gelatin microspheres (Embosphere; BioSphere Medical, Rockland, Massachusetts) are used in the treatment of epistaxis (category III). ${ }^{110,111}$ The complication rates and success of embolization or surgical ligation are similar, though embolization is associated with more major complications when embolic agents inadvertently enter the internal carotid or ophthalmic artery. ${ }^{111}$

Preoperative embolization of intracranial tumors with embolic agents before surgical resection is performed in selected cases. Most often these are hypervascular skull base tumors, including meningiomas, paragangliomas, and juvenile nasopharyngeal angiofibromas (category III). ${ }^{112-114}$ These procedures are associated with low complications mostly related to thromboembolic events. ${ }^{113}$

\section{Coils for Parent Artery or Venous Sinus Occlusion}

Approved Use. Embolization of intracranial aneurysms.

Off-Label Use. Embolization of the parent artery or venous sinus for achieving therapeutic occlusion (category III).

Coil embolization (HydroCoil; MicroVention Terumo, Aliso Viejo, California and GDC and Complex Helical; Boston Scientific) of intracranial aneurysms is a proved and effective treat- ment. However, occlusion of the parent vessel may be necessary in certain situations when treating intracranial aneurysms. Most commonly, it is used when treating distal small intracranial aneurysms that cannot be accessed (category III). ${ }^{115-118}$ In a small series of 9 patients, Eckard et $\mathrm{al}^{118}$ found that parent vessel occlusion was safe and effective in treating distal aneurysms that were not amenable to surgical treatment or intra-aneurysmal coil placement. The main risk of parent vessel occlusion is brain ischemia. Temporarily inflating a balloon to occlude the parent vessel and evaluating the effects on brain function and hemodynamics can be used to predict the risk of ischemia. ${ }^{119}$ Ischemic sequelae may still occur even in those who tolerate a test occlusion, which has a $3.3 \%-10 \%$ false-negative rate. ${ }^{119}$

Embolization of the venous sinus is sometimes used to treat dural arteriovenous fistulas. ${ }^{120-122}$ Kirsch et $\mathrm{al}^{120}$ reported no complications related to transvenous coiling of the affected sinus in 21 patients with dural arteriovenous fistulas. Complete occlusion of the dural arteriovenous fistulas can be obtained in most cases with only transvenous coil placement (category III). ${ }^{120,122}$ In addition, the use of coils before liquid embolic agents slows and decreases flow in the fistula and provides secure anchoring to the Onyx or glue cast. ${ }^{123}$

\section{Amplatzer for Intracranial Parent Vessel Occlusion}

Approved Use. Cardiopulmonary and peripheral vascular occlusions.

Off-Label Use. Parent artery deployment for achieving therapeutic occlusion of cervical arteries (category IV).

The Amplatzer Vascular Plug (St. Jude Medical, St Paul, Minnesota) is approved for vessel occlusion in the cardiopulmonary and peripheral vasculature that would have required many coils. However, experience in the intracranial vasculature is limited. Common indications for parent vessel occlusion might include treating carotid cavernous fistulas and aneurysms and preoperative embolization of skull base tumors. Several small case series have reported good technical outcome and safety when the Amplatzer Vascular Plug was used in the intracranial vasculature (category IV). ${ }^{124,125}$

\section{SINGLE-CENTER EXPERIENCE}

We retrospectively reviewed the medical records and angiographic images of 100 consecutive cases of endovascular interventions at 2 institutions. The patients were identified by using local registries maintained by the cerebrovascular/endovascular programs that track all patients who undergo endovascular treatment. The patients reviewed were treated at the University of Minnesota Medical Center, Minneapolis, Minnesota, from June 2010 -August 2010. The protocol for collecting data was reviewed and approved by the institutional review boards.

In the 100 cases reviewed, the indications for the procedures were the following: cerebral vasospasm following SAH (31\%), coil embolization of intracranial aneurysms (16\%), carotid artery stenosis (15\%), IA thrombolytics for ischemic stroke (13\%), intracranial angioplasty and/or stent placement for intracranial stenosis $(7 \%)$, preoperative tumor embolization $(8 \%)$, intracranial vascular malformation $(5 \%)$, carotid or vertebral artery dissections (3\%), and facial trauma/epistaxis (2\%).

AJNR Am J Neuroradiol 34:2054-63 Nov 2013 www.ajnr.org 
Principles of label use of medication and/or devices in neuroendovascular procedures

Principles

1. Identify off-label use and understand the use according to label/indications

2. Categorize the off-label use according to categories presented in the On-line Table

3. Category III requires informed consent for medication/device use with a description of adverse events observed in neurovascular procedures

4. Category IV requires informed consent for medication/device use with a description of adverse events observed in nonneurovascular procedures and acknowledgment of paucity of data from neurovascular procedures

Following the classification scheme in the On-line Table, all the procedures were performed under heparin infusion (category II): IA nicardipine or verapamil (category III) in 31 cases; dual antiplatelet therapy (category II) in 24 cases; IA thrombolytics (category I) in 13 cases; stent-assisted embolization of intracranial aneurysms (category I) in 3 cases; stent placement of intracranial stenosis (category I) in 4 cases; angioplasty alone of intracranial stenosis (category III) in 3 cases; stent placement of carotid or vertebral dissections (category III) in 5 cases; the intravasular ultrasound catheter system in 3 cases (category III); and polyvinyl alcohol embolization of the internal maxillary artery (category III) in 2 cases.

\section{RECOMMENDATIONS FROM PROFESSIONAL SOCIETIES}

The FDA states, "Good medical practice and the best interests of the patient require that physicians use legally available drugs, biologics and devices according to their best knowledge and judgment." ${ }^{1}$ The FDA recommends that if a physician uses an off-label drug or medical device, he or she should base judgment on sound medical evidence and should maintain a record of the products used and effects. ${ }^{1}$ A proposed scheme to categorize the off-label use of medications and devices is summarized in the On-line Table.

The position of the Society of Interventional Radiology supports the lawful use by a physician of an FDA-approved medical device or drug product for an unlabeled indication when such use is based on sound scientific evidence and/or sound medical opinion. ${ }^{126}$ Off-label use of drugs and devices is an important part of the specialty but practicing providers should base their decisions on sound evidence when using them.

Disclosures: Adnan I. Qureshi—RELATED: Grant: Dr Qureshi received funding from the National Institutes of Health RO1-NS44976-01A2 (medication provided by Export Service Parma), American Heart Association Established Investigator Award 0840053N, National Institutes of Health U01-NS062091-01A2, and the Minnesota Medical Foundation, Minneapolis, Minnesota. Ameer E. Hassan-UNRELATED: Payment for Lectures (including service on Speakers Bureaus): MicroVention, Comments: lecture on new Versatile range fill coils.

\section{REFERENCES}

1. FDA. "Off-Label" and Investigational Use of Marketed Drugs, Biologics, and Medical Devices: Information Sheet. August 10, 2011. http://www.fda.gov/RegulatoryInformation/Guidances/ucm 1 26486.htm. Accessed April 10, 2012

2. Parsons M. Spratt N. Bivard A. et al. A randomized trial of tenecteplase versus alteplase for acute ischemic stroke. $N$ Engl J Med 2012;366:1099-107
3. Chaudhary N. Pandey AS. Gemmete JJ. Intervention in acute cerebral ischemic stroke: a review of the role of pharmacological therapies and intra-arterial mechanical thrombectomy devices. Postgrad Med J 2011;87:714-23

4. Lee M, Hong KS, Saver JL. Efficacy of intra-arterial fibrinolysis for acute ischemic stroke: meta-analysis of randomized controlled trials. Stroke 20102:41:932-37

5. Qureshi A. Luft A, Sharma M, et al. Prevention and treatment of thromboembolic and ischemic complications associated with endovascular procedures: part I. Pathophysiological and pharmacological features. Neurosurgery 2000;46:1344-59

6. Castelluci L. FDA reapproves urokinase. October 11, 2002. The heart.org. http://www.theheart.org/article/266091.do. Accessed July 10,2012

7. Furlan A, Higashida R, Wechsler L, et al. Intra-arterial prourokinase for acute ischemic stroke: the PROACT II study - a randomized controlled trial. Prolyse in Acute Cerebral Thromboembolism. JAMA 1999;282:2003-11

8. del Zoppo GJ, Higashida RT, Furlan AJ., et al. PROACT: a phase II randomized trial of recombinant pro-urokinase by direct arterial delivery in acute middle cerebral artery stroke. Stroke 1998;29:4-11

9. Lee M. Hon, KS. Saver J. Efficacy of intra-arterial fibrinolysis for acute ischemic stroke meta-analysis of randomized controlled trials. Stroke 2010;41:932-37

10. Biondi A, Ricciardi GK, Puybasset L, et al. Intra-arterial nimodipine for the treatment of symptomatic cerebral vasospasm after aneurysmal subarachnoid hemorrhage: preliminary results. AJNR Am J Neuroradiol 2004;25:1067-76

11. Qureshi AI, Pande R, Kim S, et al. Third generation thrombolytics for the treatment of ischemic stroke. Curr Opin Investig Drugs 2002;3:1729-32

12. Topol EJ. Reperfusion therapy for acute myocardial infarction with fibrinolytic therapy or combination reduced fibrinolytic therapy and platelet glycoprotein IIb/IIIa inhibition: the GUSTO $\mathrm{V}$ randomised trial. Lancet 2001;357:1905-14

13. The EPISTENT Investigators. Randomised placebo-controlled and balloon-angioplasty-controlled trial to assess safety of coronary stenting with use of platelet glycoprotein-IIb/IIIa blockade. Lancet 1998;352:87-92

14. The CAPTURE Investigators. Randomised placebo-controlled trial of abciximab before and during coronary intervention in refractory unstable angina: the CAPTURE study. Lancet 1997;349:1429-35

15. Walsh R, Barrett K, Aguilar M, et al. Intracranial hemorrhage following neuroendovascular procedures with abciximab is associated with high mortality: a multicenter series. Neurocrit Care 2011;15:85-95

16. Memon M, Natarajan S, Sharma J, et al. Safety and feasibility of intraarterial eptifibatide as a revascularization tool in acute ischemic stroke. J Neurosurg 2011;114:1008-13

17. Ries T, Siemonsen S, Grzyska U, et al. Abciximab is a safe rescue therapy in thromboembolic events complicating cerebral aneurysm coil embolization: single center experience in 42 cases and review of the literature. Stroke 2009;40:1750-57

18. Adams HP Jr, Effron MB, Torner J, et al, for the AbESTT-II Investigators. Emergency administration of abciximab for treatment of patients with acute ischemic stroke: results of an international phase III trial: Abciximab in Emergency Treatment of Stroke Trial (AbESTT-II). Stroke 2008;39:87-99

19. Hofmann R, Kerschner K, Steinwender C, et al. Abciximab bolus injection does not reduce cerebral ischemic complications of elective carotid artery stenting: a randomized study. Stroke 2002;33:725-27

20. Chan AW, Yadav JS, Bhatt DL, et al. Comparison of the safety and efficacy of emboli prevention devices versus platelet glycoprotein IIb/IIIa inhibition during carotid stenting. Am J Cardiol 2005;95:791-95 
21. Wholey MH, Wholey MH, Eles G, et al. Evaluation of glycoprotein IIb/IIIa inhibitors in carotid angioplasty and stenting. J Endovasc Ther 2003;10:33-41

22. Qureshi AI, Saad M, Zaidat OO, et al. Intracerebral hemorrhages associated with neurointerventional procedures using a combination of antithrombotic agents including abciximab. Stroke 2002;33:1916-19

23. Katsaridis V, Papagiannaki C, Skoulios N, et al. Local intra-arterial eptifibatide for intraoperative vessel thrombosis during aneurysm coiling. AJNR Am J Neuroradiol 2008;29:1414-17

24. Park JH, Kim JE. Sheen SH, et al. Intraarterial abciximab for treatment of thromboembolism during coil embolization of intracranial aneurysms: outcome and fatal hemorrhagic complications. J Neurosurg 2008; 108:450-57

25. Chun R, Orser B, Madan M. Platelet glycoprotein IIb/IIIa inhibitors: overview and implications for the anesthesiologist. Anesth Analg 2002;95:879-88

26. Lincoff AM, Topol EJ, eds. Platelet Glycoprotein IIb/IIIa Inhibitors in Cardiovascular Disease. Totowa, New Jersey: Humana Press; 1999:169-97

27. Bhatt D, Topol E. Current role of platelet glycoprotein IIb/IIIa inhibitors in acute coronary syndromes. JAMA 2000;284:1549-58

28. Dorhout Mees SM, Rinkel G, Feigin V, et al. Calcium antagonists for aneurysmal subarachnoid hemorrhage. Cochrane Database Syst Rev 2007:CD000277

29. Pickard JD, Murray GD, Illingworth R, et al. Effect of oral nimodipine on cerebral infraction and outcome after subarachnoid haemorrhage: British aneurysm nimodipine trial. BMJ 1989;298:636-42

30. Barker F, Ogilvy C. Efficacy of prophylactic nimodipine for delayed ischemic deficit after subarachnoid hemorrhage: a metaanalysis. J Neurosurg 1996:84:405-14

31. FDA Labeling Text. Nimtop (nimodipine) capsules for oral use. January 20, 2006. http://www.accessdata.fda.gov/drugsatfda_docs/ label/2006/018869s014lbl.pdf. Accessed June 7, 2012

32. Kronvall E, Undren P, Romner B, et al. Nimodipine in aneurysmal subarachnoid hemorrhage: a randomized study of intravenous or peroral administration. J Neurosurg 2009;110:58-63

33. Jan M, Buchneit F, Tremoulet M. Therapeutic trial of intravenous nimodipine in patients with established cerebral vasospasm after rupture of intracranial aneurysms. Neurosurgery 1988;23:154-57

34. Rosenberg N, Lazzaro MA, Lopes DK, et al. High-dose intra-arterial nicardipine results in hypotension following vasospasm treatment in subarachnoid hemorrhage. Neurocrit Care 2011;15:400-04

35. Keuskamp J, Murali R, Chao K. High-dose intraarterial verapamil in the treatment of cerebral vasospasm after aneurysmal subarachnoid hemorrhage. J Neurosurg 2008;108:458-63

36. Taccone FS. Vasodilation and neuroprotection: the magnesium saga in subarachnoid hemorrhage. Crit Care Med 2010;38:1382-84

37. Suarez JI, for Participants in the International Multidisciplinary Consensus Conference on the Critical Care Management of Subarachnoid Hemorrhage. Magnesium sulfate administration in subarachnoid hemorrhage. Neurocrit Care 2011;15:302-07

38. Shah Q, Memom M, Suri MF, et al. Super-selective intra-arterial magnesium sulfate in combination with nicardipine for the treatment of cerebral vasospasm in patients with subarachnoid hemorrhage. Neurocrit Care 2009;11:190-98

39. Zaidat O. Periprocedural management of patients with endovascular treatment of intracranial atherosclerotic disease. J Neuroimaging 2009;19:35S-38S

40. Vance AZ, Jayaraman MV, Dubel GJ, et al. Safety of intravenous heparin administration after endovascular treatment of ruptured intracranial aneurysms. J Neurointervent Surg 2009;1:136-41

41. Hussein HM, Geordiadis AL, Qureshi AI. Point of care testing of anticoagulation monitoring in neuroendovascular procedures. AJNR Am J Neuroradiol 2012;33:1211-20

42. Di Nisio M, Middeldorp S, Büller, H. Direct thrombin inhibitors. N Engl J Med 2005;353:1028-40
43. Hassan AE, Memon M, Georgiadis A, et al. Safety and tolerability of high-intensity anticoagulation with bivalirudin during neuroendovascular procedures. Neurocrit Care 2011;15:96-100

44. Pandya DJ, Fitzsimmons BF, Wolfe TJ, et al. Measurement of antiplatelet inhibition during neurointerventional procedures: the effect of antithrombotic duration and loading dose. J Neuroimaging 2010;20:64-69

45. van den Bergh WM, Kerr RS, Algra A, et al, for the International Subarachnoid Aneurysm Trial (ISAT) Collaborative Group. Effect of antiplatelet therapy for endovascular coiling in aneurysmal subarachnoid hemorrhage. Stroke 2009;40:1969-72

46. Yamada NK, Cross DT 3rd, Pilgram TK, et al. Effect of antiplatelet therapy on thromboembolic complications of elective coil embolization of cerebral aneurysms. AJNR Am J Neuroradiol 2007;28:1778-82

47. Kang HS, Han M, Kwon, B, et al. Is clopidogrel premedication useful to reduce thromboembolic events during coil embolization for unruptured intracranial aneurysms? Neurosurgery 2010;67: $1371-76$

48. Bristol-Myers Squibb/Sanofi Pharmaceuticals Partnership. Highlights of Prescribing Information. December 2011, 2012. http:// www.accessdata.fda.gov/drugsatfda_docs/label/2011/020839s055 lbl.pdf. Accessed July 3, 2012

49. Mas JL, Trinquart L, Leys D, et al. Endarterectomy Versus Angioplasty in Patients with Symptomatic Severe Carotid Stenosis (EVA-3S) trial: results up to 4 years from a randomised, multicentre trial. Lancet Neurol 2008;7:885-92

50. Hassan AE, Zacharatos H, Vazquez G, et al. Low risk of intracranial and systemic hemorrhages in patients on dual antiplatelet treatment beyond 1 month following neuroendovascular angioplasty and/or stent placement. J Neuroimaging 2012;22:67-73

51. Qureshi AI, Feldmann E, Gomez CR, et al. Consensus conference on intracranial atherosclerotic disease: rationale, methodology, and results. J Neuroimaging 2009;19(suppl 1):1S-10S

52. Chimowitz MI, Lynn MJ, Derdeyn CP, for the SAMMPRIS Trial Investigators. Stenting versus aggressive medical therapy for intracranial arterial stenosis. N Engl J Med 2011;365:993-1003

53. Brott TG, Hobson RW II, Howard G, et al for the CREST Investigators. Stenting versus Endarterectomy for Treatment of CarotidArtery Stenosis. N Engl J Med 2010;363:11-23

54. Yadav JS, Wholey MH, Kuntz RE, et al for the Stenting and Angioplasty with Protection in Patients at High Risk for Endarterectomy Investigators. Protected carotid-artery stenting versus endarterectomy in high-risk patients. N Engl J Med 2004;351:1493-501

55. Ederle J, Dobson J, Featherstone RL, et al for the International Carotid Stenting Study investigators. Carotid artery stenting compared with endarterectomy in patients with symptomatic carotid stenosis (International Carotid Stenting Study): an interim analysis of a randomised controlled trial. Lancet 2010;375:985-997

56. Ringleb PA, Allenberg J, Brückmann H, et al for the SPACE Collaborative Group. 30 day results from the SPACE trial of stent-protected angioplasty versus carotid endarterectomy in symptomatic patients: a randomised non-inferiority trial. Lancet 2006;368;1239-47

57. Costalat V, Maldonado IL, Zerlauth JB, et al. Endovascular treatment of symptomatic intracranial arterial stenosis: six-year experience in a single-center series of 42 consecutive patients with acute and mid-term results. Neurosurgery 2010;67:1505-13

58. Jiang WJ, Wang YJ, Du B, et al. Stenting of symptomatic M1 stenosis of middle cerebral artery: an initial experience of 40 patients. Stroke 2004;35:1375-80

59. Lylyk P, Vila JF, Miranda C, et al. Endovascular reconstruction by means of stent placement in symptomatic intracranial atherosclerotic stenosis. Neurol Res 2005;27(suppl 1):S84-88

60. Mori T, Kazita K, Chokyu K, et al. Short-term arteriographic and clinical outcome after cerebral angioplasty and stenting for intracranial vertebrobasilar and carotid atherosclerotic occlusive disease. AJNR J Neuroradiol 2000;21:249-54

61. Fiorella D, Chow MM, Anderson M, et al. A 7-year experience with 
balloon-mounted coronary stents for the treatment of symptomatic vertebrobasilar intracranial atheromatous disease. Neurosurgery 2007;61:236-42

62. Gupta R, Al-Ali F, Thomas AJ, et al. Safety, feasibility, and shortterm follow-up of drug-eluting stent placement in the intracranial and extracranial circulation. Stroke 2006;37:2562-66

63. Abou-Chebl A, Bashir Q, Yadav JS. Drug-eluting stents for the treatment of intracranial atherosclerosis: initial experience and midterm angiographic follow-up. Stroke 2005;36:e165-68

64. Vajda Z, Guthe T, Perez MA. Neurovascular in-stent stenoses: treatment with conventional and drug-eluting balloons. AJNR Am J Neuroradiol 2011;32:1942-47

65. Fields JD, Petersen BD, Lutsep HL, et al. Drug eluting stents for symptomatic intracranial and vertebral artery stenosis. Interv Neuroradiol 2011;17:241-47

66. Siddiq F, Vasquez G, Memon M, et al. Comparison of primary angioplasty with stent placement for treating symptomatic intracranial atherosclerotic diseases a multicenter study. Stroke 2008;39:2505-10

67. The SSYLVIA Study Investigators. Stenting of Symptomatic Atherosclerotic Lesions in the Vertebral or Intracranial Arteries (SSYLVIA). Stroke 2004;35:1388-92

68. Takayama T, Hiro T, Hirayama A. Stent thrombosis and drug-eluting stents. J Cardiol 2011;58:92-98

69. Derdeyn C, Chimowitz M. Angioplasty and stenting for atherosclerotic intracranial stenosis: rationale for a randomized clinical trial. Neuroimaging Clin N Am 2007;17:355-63, viii-ix

70. Ding D, Liu KC. Applications of stenting for intracranial atherosclerosis. Neurosurg Focus 2011;30:E15

71. King SB 3rd, Smith SC Jr, Hirshfeld JW Jr, et al. 2007 Focused update of the ACC/AHA/SCAI 2005 Guideline Update for Percutaneous Coronary Intervention: a report of the American College of Cardiology/American Heart Association Task Force on Practice Guidelines-2007 writing group to review new evidence and update the ACC/AHA/SCAI 2005 Guideline Update for Percutaneous Coronary, Writing on Behalf of the 2005 Writing Committee. Circulation 2008;117:261-295

72. Cruz-Flores S, Diamond AL. Angioplasty for intracranial artery stenosis. Cochrane Database Syst Rev 2006;CD004133

73. Qureshi AI, Tariq N, Hassan AE, et al. Predictors and timing of neurological complications following intracranial angioplasty and/or stent placement. Neurosurgery 2011;68:53-60

74. Kurre W, Brassel F, Bruning R, et al, for the INTRASTENT study group. Complication rates using balloon-expandable and self-expanding stents for the treatment of intracranial atherosclerotic stenoses: analysis of the INTRASTENT multicentric registry. $\mathrm{Neu}$ roradiology 2012;54:43-50

75. Jiang W, Xu X, Jin M, et al. Apollo stent for symptomatic atherosclerotic intracranial stenosis: study results. AJNR Am J Neuroradiol 2007;28:830-34

76. Siddiq F, Memon M, Vazquez G, et al. Comparison between primary angioplasty and stent placement for symptomatic intracranial atherosclerotic disease: meta-analysis of case series. Neurosurgery 2009;65:1024-33

77. Hauck E. Natarajan S. Horvathy D, et al. Stent-assisted basilar reconstruction for a traumatic vertebral dissection with a large basilar artery thrombosis. J Neurointerv Surg 2011;3:47-49

78. Yi A, Palmer E, Luh G, et al. Endovascular treatment of carotid and vertebral pseudoaneurysms with covered stents. AJNR Am J Neuroradiol 2008;29:983-87

79. Kadkhodayan Y, Jeck D, Moran, C, et al. Angioplasty and stenting in carotid dissection with or without associated pseudoaneurysm. AJNR Am J Neuroradiol 2005;26:2328-35

80. Hassan AE, Zacharatos H, Souslian F, et al. Long-term clinical and angiographic outcomes in patients with cervico-cranial dissections treated with stent placement: a meta-analysis of case series. J Neurotrauma 2012;29:1342-53

81. Kan P, Mokin M, Dumont T, et al. Cervical carotid artery stenosis: latest update on diagnosis and management. Curr Probl Cardiol 2012;37:127-69

82. Brooks W, McClure R, Jones $\mathrm{M}$, et al. Carotid angioplasty and stenting versus carotid endarterectomy: randomized trial in a community hospital. J Am Coll Cardiol 2001;38:1589-95

83. Parodi J, La Mura R, Ferreira, L, et al. Initial evaluation of carotid angioplasty and stenting with three different cerebral protection devices. J Vasc Surg 2000;32:1127-36

84. Wichman HJ, Rowe VL. Percutaneous transluminal angioplasty balloons. Medscape. February 15, 2012. http://emedicine.medscape. com/article/2035433-overview\#aw2aab6b2. Accessed July 13, 2012

85. Terry A, Zipfel G, Milner E, et al. Safety and technical efficacy of over-the-wire balloons for the treatment of subarachnoid hemorrhage-induced cerebral vasospasm. Neurosurg Focus 2006;21:E14

86. Eskridge JM, McAuliffe W, Song JK, et al. Balloon angioplasty for the treatment of vasospasm: results of first $\mathbf{5 0}$ cases. Neurosurgery 1998;42:510-16, discussion 516-17

87. Zubkov YN, Alexander LF, Smith RR, et al. Angioplasty of vasospasm: is it reasonable? Neurol Res 1994;16:9-11

88. Miley J, Tariq N, Souslian F, et al. Comparison between angioplasty using compliant and noncompliant balloons for treatment of cerebral vasospasm associated with subarachnoid hemorrhage. Neurosurgery 2011;69(2 suppl operative):ons161-68, discussion ons 168

89. Newell DW, Eskridge J, Mayberg M, et al. Endovascular treatment of intracranial aneurysms and cerebral vasospasm. Clin Neurosurg 1992;39:348-60

90. Eskridge JM Newell, DW, Pendleton, GA. Transluminal angioplasty for treatment of vasospasm. Neurosurg Clin $N \mathrm{Am}$ 1990;1:387-99

91. Takahashi A, Yoshoto T, Mizou K, et al. Transluminal balloon angioplasty for cerebral vasospasm after subarachnoid hemorrhage. In: Sano K, Takakura K, Kassell N, et al. (eds). Cerebral Vasospasm, Tokyo: University of Tokyo Press; 1990, pp. 429-32

92. Zacharatos H, Hassan AE, Qureshi, AI. Intravascular ultrasound: principles and cerebrovascular applications. AJNR Am J Neuroradiol 2010;31:586-97

93. Clark DJ, Lessio S, O'Donoghue M, et al. Safety and utility of intravascular ultrasound guided carotid artery stenting. Catheter Cardiovasc Interv 2004;63:355-62

94. Weissman N, Canos M, Mintz G, et al. Carotid artery intravascular ultrasound: safety and morphologic observations during carotid stenting in 102 patients. J Am Coll Cardiol 2000;35(2 supple 1):10A

95. Manninen HI, Räsänen H, Vanninen RL, et al. Human carotid arteries: correlation of intravascular US with angiographic and histopathologic findings. Radiology 1998;206:65-74

96. Kan P, Mokin M, Abla AA, et al. Utility of intravascular ultrasound in intracranial and extracranial neurointerventions: experience at University at Buffalo Neurosurgery-Millard Fillmore Gates Circle Hospital. Neurosurg Focus 2012;2:E6

97. Strozyk D, Baccin CE, Pryor JC, et al. Intracranial arteriovenous malformations. In: Quershi AI, ed. Textbook of Interventional Neurology. New York: Cambridge University Press; 2011:255

98. Oh D, Hirsch J, Yoo, A. Novel use of Onyx for treatment of intracranial vertebral artery dissection. J Neurointerv Surg 2012;4:31-33

99. Tevah J, Senf R, Cruz J, et al. Endovascular treatment of complex cerebral aneurysms with Onyx HD-500 in 38 patients. J Neuroradiol 2011;38:283-90

100. Simon SD, Lopes DK, Mericle RA. Use of intracranial stenting to secure unstable liquid embolic casts in wide-neck sidewall intracranial aneurysms. Neurosurgery 2010;66(3 suppl operative):92-97, discussion $97-98$

101. Medel R, Crowley RW, Hamilton DK, et al. Endovascular obliteration of an intracranial pseudoaneurysm: the utility of Onyx. J Neurosurg Pediatr 2009;4:445-48

102. Eddleman CS, Surdell D, DiPatri A Jr, et al. Infectious intracranial aneurysms in the pediatric population: endovascular treatment with Onyx. Childs Nerv Syst 2008;24:909-15 
103. Isokangas JM, Siniluoto T, Tikkakoski T, et al. Endovascular treatment of peripheral aneurysms of the posterior inferior cerebellar artery. AJNR Am J Neuroradiol 2008;29:1783-88

104. Choulakian A, Drazin D, Alexander MJ. NBCA embolization of a ruptured intraventricular distal anterior choroidal artery aneurysm in a patient with Moyamoya disease. J Neurointerv Surg 2010;2:368-70

105. Larrazabal R, Pelz D, Findlay JM. Endovascular treatment of a lenticulostriate artery aneurysm with N-butyl cyanoacrylate. Can J Neurol Sci 2001;28:256-59

106. Kim SH, Kwon O-Ki, Jung CK, et al. Endovascular treatment of ruptured aneurysms of pseudoaneurysms on the collateral vessels in patients with Moyamoya disease. Neurosurgery 2009;65: 1000-04

107. Piske RL, Kanashiro LH, Paschoal E, et al. Evaluation of Onyx HD500 embolic system in the treatment of 84 wide-neck intracranial aneurysms. Neurosurgery 2009;64:E865-75

108. Dudeck O, Jordan O. Hoffmann KT, et al. Embolization of experimental wide-necked aneurysms with iodine-containing polyvinyl alcohol solubilized in a low-angiotoxicity solvent. AJNR Am J Neuroradiol 2006;27:1849-55

109. Ohta $\mathrm{M}$, Handa $\mathrm{A}$, Iwata $\mathrm{H}$, et al. Poly-vinyl alcohol hydrogel vascular models for in vitro aneurysm simulations: the key to low friction surfaces. Technol Health Care 2004;12:225-33

110. Andersen P, Kjeldsen, A, Nepper-Rasmussen J. Selective embolization in the treatment of intractable epistaxis. Acta Otolaryngol 2005;125:293-97

111. Willems P, Farb R, Agid R. Endovascular treatment of epistaxis. AJNR Am J Neuroradiol 2009;30:1637-45

112. Gruber A, Bavinski G, Killer M, et al. Preoperative embolization of hypervascular skull base tumors. Minim Invasive Neurosurg 2000;43:62-71

113. Manelfe C, Lasjaunias $P$, Ruscalleda J. Preoperative embolization of intracranial meningiomas. AJNR Am J Neuroradiol 1986;7:963-72

114. Perry A, Chicione MR, Filiput E, et al. Clinicopathologic assessment and grading of embolized meningiomas: a correlative study of 64 patients. Cancer 2001;92:701-11

115. Liu L, He H, Jiang C, et al. Deliberate parent artery occlusion for non-saccular posterior cerebral artery aneurysms. Interv Neuroradiol 2011;17:159-68

116. Lv X, Li Y, Jiang C, et al. Parent vessel occlusion for P2 dissecting aneurysms of the posterior cerebral artery. Surg Neurol 2009;71: 319-25, discussion 325

117. Pierot L, Boulin A, Castaings L, et al. The endovascular approach in the management of patients with multiple intracranial aneurysms. Neuroradiology 1997;39:361-66

118. Eckard D, O’Boynick P, McPherson C, et al. Coil occlusion of the parent artery for treatment of symptomatic peripheral intracranial aneurysms. AJNR Am J Neuroradiol 2000;21:137-42

119. Linskey ME, Jungreis CA, Yonas $H$, et al. Stroke risk after abrupt internal carotid artery sacrifice: accuracy of preoperative assessment with balloon test occlusion and stable xenon-enhanced CT. AJNR Am J Neuroradiol 1994;15:829-43

120. Kirsch M, Liebig T, Kühne D, et al. Endovascular management of dural arteriovenous fistulas of the transverse and sigmoid sinus in 150 patients. Neuroradiology 2009;51:477-83

121. Shi Z, Loh Y, Gonzalez, N, et al. Flow control techniques for Onyx embolization of intracranial dural arteriovenous fistulae. J Neurointervent Surg 2013;5:311-16

122. Quiñones D, Duckwiler G, Gobin PY, et al. Embolization of dural cavernous fistulas via superior ophthalmic vein approach. $A J N R$ Am J Neuroradiol 1997;18:921-28

123. Gupta AK, Periakaruppan AL. Intracranial dural arteriovenous fistulas: a review. Indian J Radiol Imaging 2009;19:43-48

124. Ong CK, Lam DV, Ong MT, et al. Neuroapplication of Amplatzer Vascular Plug for therapeutic sacrifice of major craniocerebral arteries: an initial clinical experience. Ann Acad Med Singapore 2009;38:763-68

125. Gralla J, Schroth G, Kickuth R, et al. Closing the gap between coil and balloon in the neurointerventional armamentarium? Initial clinical experience with a nitinol vascular occlusion plug. Neuroradiology 2008;50:709-14

126. Society of Interventional Radiology Executive Council. SIR Policy on Off-Label Use. November 18, 2007. http://sirweb.org/clinical/ cpg/SIR_Off-label_use_statement11-18-07.pdf. Accessed July 12, 2012 